\title{
Evaluación Morfológica de Ovocitos Caninos Recuperados en Diferentes Fases del Ciclo Estral
}

\author{
Morphological Evaluation of Canine Oocytes Recovered in Different Phases \\ of The Estrous Cycle
}

\author{
Alfonso Sánchez R. ${ }^{1,2}$, Carolina Ahumada C. ${ }^{1}$
}

\section{Resumen}

\begin{abstract}
El objetivo del estudio fue obtener y evaluar morfológicamente ovocitos caninos procedentes de hembras en las diferentes fases del ciclo estral y comparar las proporciones de ovocitos potencialmente aptos para maduración in vitro (MIV). Se obtuvieron los ovarios de 24 perras, 6 por cada fase del ciclo estral, y mediante cortes finos se recuperaron los ovocitos, que fueron clasificados morfológicamente como aptos y no aptos para MIV. Dentro de los ovocitos recuperados como aptos para MIV, el 86.6\% fue recuperado de hembras en proestro y estro $(\mathrm{p}<0.01)$. La mayor cantidad de ovocitos aptos para MIV por hembra $(448.0 \pm 52.7)$ se obtuvo en la fase de estro $(\mathrm{p}<0.01)$. Se concluye que la evaluación morfológica de los ovocitos permitió establecer que la calidad y cantidad de ovocitos recuperados durante las fases de estro y proestro del ciclo estral, en términos de su potencial uso para MIV, fueron mejores y mayores a los ovocitos obtenidos en anestro y diestro.
\end{abstract}

Palabras clave: ovocito canino, maduración in vitro

\section{Abstract}

The aim of the study was to obtain and morphologically evaluate canine oocytes from females at different phases of the estrous cycle and to compare the proportions of oocytes potentially suitable for in vitro maturation (IVM). Ovaries of 24 bitches, 6 for each phase of the estrous cycle, were sliced to recover the oocytes. These were morphologically classified into fit and unfit oocytes for IVM. The largest proportion of oocytes fit for IVM $(86.6 \%)$ was recovered from females in proestrus and estrus $(\mathrm{p}<0.01)$ and the largest quantity of oocytes fit for IVM per female $(448.0 \pm 52.7)$ was obtained in

\footnotetext{
${ }^{1}$ Escuela de Medicina Veterinaria, Universidad Santo Tomás, Viña del Mar, Chile

${ }^{2}$ E-mail: teriogenologiachile@vtr.net
}

Recibido: 19 de enero de 2015

Aceptado para publicación: 4 de mayo de 2015 
the estrus phase $(\mathrm{p}<0.01)$. It is concluded that the morphological assessment of oocytes indicated that the quality and quantity of oocytes recovered during the oestrus and proestrus phase of the oestrus cycle in terms of their potential use for IVM were better and higher than those obtained during the anestrus and diestrus phases.

Key words: canine oocyte, in vitro maduration

\section{INTRODUCCIÓN}

El estudio de la biología reproductiva de la perra doméstica (Canis lupus familiaris) constituye un valioso modelo para la comprensión y desarrollo de biotecnologías reproductivas con aplicación en especies de cánidos en peligro de extinción (Farstad, 2000; Luvoni, 2000). Además, las técnicas de maduración de ovocitos in vitro (MIV) y fecundación in vitro (FIV) representan una alternativa para rescatar material genético en hembras de alto valor y que presentan alteraciones reproductivas no hereditarias (Hishinuma et al., 2004).

Existe concordancia en destacar que debido a la particular fisiología reproductiva de la perra, los progresos en el área de la reproducción asistida han sido relativamente lentos al compararlos con otras especies, siendo el aspecto más determinante de esta situación la complejidad del gameto femenino, el cual se caracteriza por ser ovulado en estado de ovocito I (vesícula germinal), requiriendo reasumir y completar su proceso meiótico en el oviducto, y así la madurez, entre 56 a 72 horas después de la ovulación (Luvoni et al., 2005; Reynaud et al., 2005).

Desde el primer reporte de MIV en ovocitos de perras (Mahi y Yanagimachi, 1976), se han realizado múltiples ensayos con el propósito de generar un sistema eficiente de maduración ovocitaria en cultivo para esta especie. Las características especiales y únicas de ovular un ovocito I y el largo tiempo de maduración en el oviducto han dificultado en gran medida los intentos de reproducir la
MIV y la FIV en los ovocitos caninos, teniéndose a la fecha un éxito muy limitado. Por tanto, considerando que aún no hay suficientes antecedentes de los mecanismos que controlan la maduración del ovocito, las investigaciones se han enfocado a identificar algunos factores intrínsecos y extrínsecos que influyen en la maduración ovocitaria de esta especie (De los Reyes, 2011).

En términos generales, los ovocitos caninos utilizados para MIV provienen de folículos de diferentes tamaños, mostrando un bajo grado de maduración en cultivos utilizando medios adaptados de técnicas de MIV desarrolladas en otras especies. Esto ha motivado el estudio de factores que pudiesen influir en una mayor tasa de maduración ovocitaria. Entre los factores estudiados cabe destacar: edad de la perra (Nickson et al., 1993; Ström Holst et al., 2001), tamaño del ovocito (Hewitt y England, 1998a), densidad en el cultivo (Otoi et al., 2002), morfología ovocitaria (Nickson et al., 1993), sistemas de co-cultivo (Hewitt y England, 1998b; Rodrigues y Rodrigues, 2003) y suplementaciones al medio de cultivo (De los Reyes et al., 2005; Bolamba et al., 2006; Vannucchi et al., 2009).

Un factor intrínseco que es señalado como controversial en los resultados de la MIV canina, es la influencia que podría ejercer el estado del ciclo estral de la hembra al momento de ser obtenidos los ovarios para la extracción de ovocitos (Evecen et al., 2010; Chastant-Maillard et al., 2012). Esto se fundamenta en las notables variaciones en el ambiente hormonal de las hembras a través del ciclo estral. La perra es una hembra 
monoéstrica, no estacional y de ovulación espontánea, con una a tres ovulaciones por año, donde cada ciclo estral está constituido por cuatro etapas o fases: anestro, proestro, estro y diestro. Hormonalmente el anestro se caracteriza por la ausencia de actividad esteroidogénica en los ovarios, el proestro es la etapa de mayor actividad folicular con un neto predominio estrogénico, el estro se relaciona con una disminución en los niveles de estrógenos e incremento de progesterona asociado a la ovulación y presencia de cuerpos lúteos y el diestro es la fase de predominio progestagénico (Concannon, 2011).

Dados los antecedentes, el objetivo del presente estudio fue obtener y evaluar morfológicamente ovocitos caninos procedentes de hembras en las diferentes etapas del ciclo estral y comparar las proporciones de ovocitos potencialmente aptos para MIV.

\section{Materiales y Métodos}

\section{Obtención de Ovarios y Fase del Ciclo Estral}

La investigación se desarrolló en el Hospital Clínico Veterinario de la Universidad Santo Tomás, Viña del Mar, Chile. Se ovariohisterectomizaron 30 hembras caninas adultas (2 a 6 años), clínicamente sanas, con un peso corporal que fluctuó entre 10 y $30 \mathrm{~kg}$.

En cada hembra se estableció la fase del ciclo estral mediante citología vaginal y estudio macroscópico de la superficie de ambos ovarios, definiendo la presencia o ausencia de folículos $\geq 5 \mathrm{~mm}$ y cuerpos lúteos. El edema y sangrado vulvar fueron considerados en el diagnóstico del proestro. Se descartaron seis hembras con patologías o alteraciones macroscópicas de los ovarios.

Una vez definida la fase del ciclo estral, se distribuyeron seis hembras por fase. Los ovarios obtenidos fueron almacenados y transportados al laboratorio en solución
Dulbecco's fosfato buffer salino (PBS) en un frasco estéril.

\section{Obtención de Ovocitos}

Los ovarios, luego de la evaluación macroscópica, fueron trasladados a placas Petri que contenían solución PBS, para la obtención de ovocitos mediante cortes de la corteza ovárica (slicing). Se hicieron cortes seriados, de aproximadamente $2 \mathrm{~mm}$, en sentido longitudinal y transversal, utilizando hojas de bisturí oftálmico y bajo observación con lupa estereoscópica (Fujii et al., 1999).

Para mejorar la observación y recolección de los ovocitos, se agregaron 5 gotas de eosina al 5\% al medio. Cada placa se dejó sedimentar por 5 min y el sedimento fue diluido en otra placa a fin de observar más claramente y recuperar los ovocitos. Estos fueron recolectados con micropipetas adelgazadas en uno de sus extremos y conectadas a una jeringa de $1 \mathrm{ml}$. Los ovocitos fueron traspasados a otra placa que contenía 4 gotas de solución PBS para su clasificación.

\section{Clasificación de Ovocitos}

Mediante una lupa estereoscópica (40X) se clasificaron los ovocitos siguiendo el criterio propuesto por Wood y Wildt (1997), en el cual se evalúa la integridad/homogeneidad del citoplasma y la presencia y número de capas del cumulus oophorus. Se describen cuatro categorías: Categoría I (excelente): con citoplasma fácil de identificar, homogéneo, oscuro, núcleo esférico y excéntrico, con cinco o más capas completas de células de cúmulo; Categoría II (bueno): con citoplasma homogéneo y oscuro, núcleo esférico y excéntrico, con 2 a 4 capas completas de células de cúmulo; Categoría III (regular): el citoplasma poco homogéneo, aspecto vacuolado y de transparencia por fragmentación, y con 1 a 2 capas de células de cúmulo, que pueden estar incompletas; Categoría IV (pobre): citoplasma heterogéneo, con transparencia, fragmentación, y no posee cúmulo o sus células están dispersas. Los 
Cuadro 1. Número y calidad de ovocitos recuperados de 48 ovarios de perras según fase del ciclo estral de las perras ${ }^{1}$

\begin{tabular}{cccc}
\hline \multirow{2}{*}{$\begin{array}{c}\text { Fase del ciclo } \\
\text { estral }\end{array}$} & \multicolumn{2}{c}{$\begin{array}{c}\text { Ovocitos para maduración in vitro } \\
(\mathrm{n})\end{array}$} & $\begin{array}{c}\text { Total de } \\
\text { ovocitos } \\
\text { An) }\end{array}$ \\
\cline { 2 - 3 } & Aptos & No aptos & $445^{\mathrm{a}}$ \\
\hline Anestro & $131^{\mathrm{a}}$ & $314^{\mathrm{a}}$ & $3161^{\mathrm{b}}$ \\
Proestro & $2324^{\mathrm{b}}$ & $837^{\mathrm{b}}$ & $3555^{\mathrm{b}}$ \\
Estro & $2688^{\mathrm{b}}$ & $867^{\mathrm{b}}$ & $589^{\mathrm{a}}$ \\
Diestro & $232^{\mathrm{a}}$ & $357^{\mathrm{a}}$ & 7750 \\
\hline Total & 5375 & 2375 & \\
\hline${ }^{\mathrm{a}, \mathrm{b}}$ Diferentes superíndices dentro de columnas indican diferencias significativas $(\mathrm{p} \varangle 0.01)$ \\
${ }^{1}$ Seis perras por fase
\end{tabular}

Cuadro 2. Promedio \pm desviación estándar de ovocitos potencialmente aptos para maduración in vitro obtenidos por perra y por fase del ciclo estral (6 perras por fase)

\begin{tabular}{lcccc}
\hline Ovocitos & Anestro & Proestro & Estro & Diestro \\
\hline Hembra & $21.8 \pm 4.0^{\mathrm{d}}$ & $387.3 \pm 59.4^{\mathrm{b}}$ & $448.0 \pm 52.7^{\mathrm{a}}$ & $38.7 \pm 19.2^{\mathrm{c}}$ \\
Fase & $74.2 \pm 9.2^{\mathrm{d}}$ & $526.8 \pm 71.8^{\mathrm{b}}$ & $592.5 \pm 53.0^{\mathrm{a}}$ & $98.2 \pm 12.7^{\mathrm{c}}$ \\
\hline
\end{tabular}

a,b,c,d Diferentes superíndices dentro de filas indican diferencias significativas $(p \varangle 0.01)$

ovocitos de las categorías I y II se consideraron potencialmente aptos para MIV y los de las categorías III y IV no aptos para MIV.

\section{Análisis Estadístico}

Para el análisis estadístico de las categorías de ovocitos según fase del ciclo estral se utilizó la prueba de Chi-cuadrado. Se utilizó la prueba de rangos múltiples LSD de Fisher para determinar diferencias entre grupos. Las tasas de recuperación de ovocitos potencialmente aptos para MIV por hembra y por fase del ciclo estral se analizaron mediante la prueba binominal de proporciones. En ambos análisis se consideró un valor de p $<0.01$ como estadísticamente significativo. Se utilizó el programa computacional Win Episcope 2.0.

\section{Resultados y Discusión}

La evaluación de los ovarios permitió establecer una fase sin estructuras (anestro), dos fases con presencia de folículos $\geq 5 \mathrm{~mm}$ y sin cuerpos lúteos (proestro-estro) y otra fase con solo presencia de cuerpos lúteos (diestro); criterios que concuerdan con Otoi et al. (2002) y Evecen et al. (2010).

Se registraron $8.3 \pm 5.8$ y $11.5 \pm 2.9$ folículos $\geq 5 \mathrm{~mm}$ en los grupos de proestro y estro, respectivamente, en tanto que en el grupo en diestro se registraron $8.6 \pm 1.5$ cuerpos lúteos. La citología vaginal tuvo como principal característica el predominio de células parabasales en anestro ( $>60 \%)$, equivalencia entre células intermedias y superfi- 
ciales, y mayor presencia de eritrocitos en proestro, predominio de células superficiales en estro $(>70 \%)$ y predominio de células intermedias en diestro, lo cual está de acuerdo con lo expuesto por otros autores (Feldman y Nelson, 1996; Concannon, 2011).

Se recolectaron 7750 ovocitos de los 148 ovarios procesados. De estos ovocitos, $5375(69.4 \%)$ fueron clasificados morfológicamente como potencialmente aptos para MIV y 2375 (30.6\%) como no aptos para MIV (Cuadro 1). No se observaron diferencias en el número de ovocitos recolectados entre los ovarios izquierdo y derecho en cada fase del ciclo estral.

La mayor cantidad de ovocitos fueron recuperados en las fases de proestro y estro $(86.6 \%)$, destacándose, además, la mayor proporción de ovocitos aptos para MIV (93.2\%) en estos dos grupos. Por otro lado, no se encontraron diferencias entre ambas etapas del ciclo estral. Estos resultados coinciden parcialmente con Williangham-Rocky et al. (2003), quienes determinaron que las mayores tasas de MIV para ovocitos caninos se alcanzaron en la fase de estro, situación que podría explicarse por el estado del desarrollo folicular, donde predominaron los folículos pre-ovulatorios en los cuales los factores de crecimiento u otras vías de señalización paracrinas pueden influir en la calidad de los ovocitos (De los Reyes et al., 2014). En anestro y diestro solo se recuperó el $13.4 \%$ de los ovocitos totales, representando el $71.7 \%$ de los ovocitos clasificados como no aptos para MIV, concordando con el trabajo de Chastant-Maillard et al. (2012).

El Cuadro 2 muestra la distribución de ovocitos potencialmente aptos para MIV obtenidos por hembra según fase del ciclo estral. El mayor número de ovocitos se obtuvo durante la fase de estro $(448.0 \pm 52.7)$ y el menor durante el anestro (21.8 \pm 4.0$)$, habiendo diferencias significativas en el número de ovocitos por cada fase del ciclo estral.
$\mathrm{Al}$ analizar los resultados de las categorías de ovocitos potencialmente aptos para MIV, utilizando el coeficiente de variación $(\mathrm{CV}$ $=$ media/desviación estándar x 100) como una medida de dispersión, se encontraron $\mathrm{CV}$ de $18.3,15.3,11.8$ y $49.6 \%$ para el anestro, proestro, estro y diestro, respectivamente, rangos que fueron comunes para variables biológicas (Zar, 1999). No obstante, en la fase de diestro se observó una alta dispersión en los valores promedios de ovocitos aptos para MIV, lo que podría deberse a la presencia de cuerpos lúteos en los ovarios, que dificultaron el proceso de corte de los ovarios, alterando la recolección de ovocitos.

Se concluye que la evaluación morfológica de los ovocitos permitió establecer que la calidad y cantidad de ovocitos recuperados durante las fases de estro y proestro del ciclo estral, en términos de su potencial uso para MIV, fueron mejores y mayores a los ovocitos obtenidos en el anestro y diestro.

\section{Literatura Citada}

1. Bolamba D, Russ K, Harper $S$, Sandler J, Durrant B. 2006. Effects of epidermal growth factor and hormones on granulosa expansion and nuclear maturation of dog oocytes in vitro. Theriogenology 65: 1037-1047. doi: $10.1016 / \mathrm{j}$. theriogenology. 2005.06.017

2. Chastant-Maillard S, Saint-Dizier M, Grimard B, Chebrout M, Thoumire S, Reynaud K. 2012. Are oocytes from the anestrous bitch competent for meiosis? Reprod Dom Anim 47(Suppl 6): 74-79. doi: 10.1111/rda.12007

3. Concannon, P. 2011. Reproductive cycles of the domestic bitch. Anim Reprod Sci 124: 200-210. doi: 10.1016/ j.anireprosci.2010.08.028

4. De los Reyes M, de Lange J, Miranda P, Palomino J, Barros C. 2005. Effect of human chorionic gonadotropin 
supplementation during different culture periods on in vitro maturation of canine oocytes. Theriogenology 64: 1-11.

5. De los Reyes M, Palomino J, Parraguez, V, Rojas C. 2014. Factores de crecimiento durante el desarrollo folicular en la perra. En: II Simposio Latinoamericano de Reproducción Animal. Chile.

6. De los Reyes M. 2011. Maduración nuclear y citoplasmática in vitro en ovocitos de perra. Spermova 1(1): 5357.

7. Evecen M, Cirit $\ddot{U}$, Demir K, Özdap Ö, Tap M, Pabuccuoðlu S. 2010. Effects of estrous cycle stage and transport temperature of ovaries on in vitro maturation of canine oocytes. Anim Reprod Sci 117: 160-165. doi: 10.1016/ j.anireprosci.2009.03.004

8. Farstad W. 2000. Current state in biotechnology in canine and feline reproduction. Anim Reprod Sci 60: 375387. doi: 10.1016/S0378-4320(00)00106-8

9. Feldman E, Nelson R. 1996. Canine female reproduction. En: Canine and feline endocrinology and reproduction. Philadelphia, USA: WB Sunders. p 526546.

10. Fuji M, Otoi T, Murakami M, Tanaka M, Une S, Suzuki T. 1999. The quality and maduration of bitch oocytes recovered from ovaries by the slicing method. J Vet Med Sci 62: 305-307. doi: 10.1292/jvms.62.305

11. Hewitt D, England G. 1998b. The canine oocyte penetration assay; its use as an indicator of dog spermatozoa performance in vitro. Anim Reprod Sci 50: 123-139. doi: 10.1016/S0378-4320(97)00083-3

12. Hewitt D, England G. 1998a. The effect of oocyte size and bitch age upon oocyte nuclear maturation in vitro. Theriogenology 49: 957-966. doi: 10.1016/S0093-691X(98)00044-2

13. Hishinuma M, Minami S, Okamoto Y, Miyatake K, Sekine J. 2004. Recovery, morphological quality, and in vitro maturation of follicular oocytes from bitches with pyometra. Theriogenology 62:1652-1662. doi: 10.1016/j.theriogenology.2004.03.009

14. Luvoni G, Chigioni S, Allievi E, Macis D. 2005. Factors involved in vivo and in vitro maturation of canine oocytes. Theriogenology 63: 41-59. doi: 10.1016/ j.theriogenology.2004.03.004

15. Luvoni G 2000. Current progress on assisted reproduction in dogs and cats: in vitro embryo production. Reprod Nutr Dev 40: 505-512. doi: 10.1051/ rnd:2000114

16. Mahi C, Yanagimachi R. 1976. Capacitation, acrosome reaction, and egg penetration by canine spermatozoa in a simple defined medium. Gamete Res 1: 101-109. doi: 10.1002/mrd. 1120010203

17. Nickson D, Boyd J, Eckersall P, Ferguson J, Harvey M, Renton J. 1993. Molecular biology methods of monitoring oocyte maturation and in vitro fertilization in bitches. J Reprod Fertil (Suppl 47): 231-240.

18. Otoi T, Williangham L, Shin T, Kraemer D, Westhusin M. 2002. Effects of oocyte culture density on meiotic competence of canine oocytes. Reproduction 124: 775-781.

19. Reynaud K, Fontbonne A, Marseloo $N$, Thoumire S, Chebrout $M$, de Lesegno C, Chastant-Maillard S. 2005. In vivo meiotic resumption, fertilization and early embryonic development in the bitch. Reproduction 130: 193-201.

20. Rodrigues B, Rodrigues J. 2003. Influence of reproductive status on in vitro oocyte maturation in dogs. Theriogenology 60: 59-66. doi: 10.1016/ S0093-691X(02)01301-8

21. Ström-Holst B, Larsson B, RodriguezMartinez, $H$, Lagerstedt $A$, LindeForsberg C. 2001. Prediction of the oocyte recovery rate in the bitch. $\mathrm{J}$ Vet Med A Physiol Pathol Clin Med 48: 587592. doi: 10.1046/j.1439-0442.2001.00388.x 
22. Vannucchi C, Faustino M, Marques M, Nichi M, Ortiz D'Ávila Assumpção M, Visintin, J. 2009. Effects of gonadotropin-exposed medium with high concentrations of progesterone and estradiol-17 beta on in vitro maturation of canine oocytes. In Vitro Cell Dev Biol Anim 45: 328-333. doi: 10.1007/s11626009-9185-6

23. Willingham-Rocky L, Hinrichs $K$, Westhusin M, Kraemer D. 2003. Effects of stage of oestrous cycle and progesterone supplementation during culture on maturation of canine oocyte in vitro. Reproduction 126: 501-508.

24. Wood T, Wildt E. 1997. Effect of the quality of the cumulus-oocyte complex in the domestic cat on the ability of oocytes to mature, fertilize and develop into blastocysts in vitro. J Reprod Fertil 110: 355-360. doi: 10.1530/jrf.0.1100355

25. Zar J. 1999. Biostatistical analysis. $4^{\text {th }}$ ed. New Jersey, USA. Prentice Hall. 929 p. 